\title{
Consolidated Health Economic Evaluation Reporting Standards 2022 (CHEERS 2022) statement: updated reporting guidance for health economic evaluations
}

\author{
Don Husereau, Michael Drummond, Federico Augustovski, Esther de Bekker-Grob, Andrew H Briggs, Chris Carswell, \\ Lisa Caulley, Nathorn Chaiyakunapruk, Dan Greenberg, Elizabeth Loder, Josephine Mauskopf, C Daniel Mullins, \\ Stavros Petrou, Raoh-Fang Pwu, and Sophie Staniszewska
}

\section{SUMMARY}

Health economic evaluations are comparative analyses of alternative courses of action in terms of their costs and consequences. The Consolidated Health Economic Evaluation Reporting Standards (CHEERS) statement, published in 2013, was created to ensure health economic evaluations are identifiable, interpretable, and useful for decision making. It was intended as guidance to help authors report accurately which health interventions were being compared and in what context, how the evaluation was undertaken, what the findings were, and other details that may aid readers and reviewers in interpretation and use of the study. The new CHEERS 2022 statement replaces previous $\mathrm{CHEERS}$ reporting guidance. It reflects the need for guidance that can be more easily applied to all types of health economic evaluation, new methods and developments in the field, as well as the increased role of stakeholder involvement including patients and the public. It is also broadly applicable to any form of intervention intended to improve the health of individuals or the population, whether simple or complex, and without regard to context (such as health care, public health, education, social care, etc). This summary article presents the new CHEERS 2022 28-item checklist and recommendations for each

\section{Author affiliations}

Don Husereau, adjunct professor, senior associate, School of Epidemiology and Public Health, University of Ottawa, Ontario, Canada. Institute of Health Economics, Alberta, Canada; Michael Drummond, professor, Centre for Health Economics, University of York, York, UK; Federico Augustovski, director, professor of public health, principal researcher, Health Technology Assessment and Health Economics Department of the Institute for Clinical Effectiveness and Health Policy (IECS-CONICET), Buenos Aires, University of Buenos Aires, Buenos Aires, CONICET (National Scientific and Technical Research Council), Buenos Aires, Argentina; Esther de Bekker-Grob, full professor of health economics \& health preferences, Erasmus School of Health Policy \& Management, Erasmus University Rotterdam, Rotterdam, The Netherlands; Andrew H Briggs, professor of health economics, London School of Hygiene and Tropical Medicine, London, England, UK; Chris Carswell, senior editor, Adis Journals, Springer Nature, Auckland, New Zealand; Lisa Caulley, assistant professor, associate scientist, doctoral candidate, Department of Otolaryngology - Head \& Neck Surgery, University of Ottawa, Ontario, Canada. Clinical Epidemiology Program and Center for Journalology, Ottawa Hospital Research Institute, Ontario, Canada. Department of Epidemiology, Erasmus University Medical Center Rotterdam, Rotterdam, The
Netherlands; Nathorn Chaiyakunapruk, professor, Department of Pharmacotherapy, College of Pharmacy, University of Utah, Salt Lake City, Utah, USA; Dan Greenberg, professor, Department of Health Policy and Management, School of Public Health, Faculty of Health Sciences, Ben-Gurion University of the Negev, Be'er-Sheva, Israel; Elizabeth Loder, professor, head of research, Harvard Medical School, Boston, MA, USA; The BMJ, London, UK; Josephine Mauskopf, vice president, RTI Health Solutions, RTI International, Research Triangle Park, NC, USA; C Daniel Mullins, professor and chair, School of Pharmacy, University of Maryland Baltimore, Baltimore, MD, USA; Stavros Petrou, professor of health economics, Nuffield Department of Primary Care Health Sciences, University of Oxford, Oxford, UK; Raoh-Fang Pwu, National Hepatitis C Program Office, Ministry of Health and Welfare, Taipei City, Taiwan; Sophie Staniszewska, professor of health research, on behalf of CHEERS 2022 ISPOR Good Research Practices Task Force. Warwick Research in Nursing, University of Warwick Warwick Medical School, Warwick, UK.

CORRESPONDENCE:

D Husereau,donh@donhusereau.com

J Manag Care Spec Pharm 2022;28(2):146-55

Copyright $@ 2022$, Academy of Managed Care Pharmacy. All rights reserved. 


\section{SUMMARY (continued)}

item. The CHEERS 2022 statement is primarily intended for researchers reporting economic evaluations for peer reviewed journals as well as the peer reviewers and editors assessing them for publication. However, we anticipate familiarity with reporting requirements will be useful for analysts when planning studies. It may also be useful for health technology assessment bodies seeking guidance on reporting, as there is an increasing emphasis on transparency in decision making.

Economic evaluations of health interventions are comparative analyses of alternative courses of action in terms of their costs and consequences. They can provide useful information to policy makers, payers, health professionals, patients, and the public about choices that affect health and the use of resources. Economic evaluations are a particular challenge for reporting because substantial information must be conveyed to allow scrutiny of study findings. Despite a growth in published economic evaluations ${ }^{1-3}$ and availability of reporting guidance, ${ }^{4}$ there is a considerable lack of standardisation and transparency in reporting. ${ }^{5,6}$ There remains a need for reporting guidance to help authors, journal editors, and peer reviewers in their identification and interpretation.

The goal of the original Consolidated Health Economic Evaluation Reporting Standards (CHEERS) statement, ${ }^{4}$ was to recommend the minimum amount of information required for reporting of published health economic evaluations. The statement consisted of a 24-item checklist and Explanation and Elaboration Report. ${ }^{4}$ CHEERS was intended to help authors provide accurate information on which health interventions are being compared and in what context, how the evaluation was undertaken, what the findings are, and other details that may aid readers and reviewers in interpretation and use of the study. In doing so, it can also aid interested researchers in replicating research findings. Some checklist items (such as title, abstract) were also included to aid those researching economic evaluation literature. The CHEERS statement consolidated previous health economic evaluation reporting guidelines ${ }^{7-18}$ into one current, useful reporting guidance.

Since the original publication of the CHEERS statement, there have been several developments that have motivated an update. These include feedback on perceived limitations of CHEERS, including criticism of its neglect of addressing reporting of cost-benefit analyses. ${ }^{19}$ CHEERS has also been observed to be used inappropriately, as a tool to assess quality of methods, for which other tools exist, ${ }^{20}$ rather than the quality of reporting. ${ }^{5}$ It has also been used as a tool to quantitatively score studies in systematic reviews, an approach that could mislead readers and reviewers ${ }^{21}$ as it has not been designed for this purpose.

There have also been methods developments in economic evaluation motivating an update. This includes an update of methods proposed by the Second Panel on CostEffectiveness in Health and Medicine ("Second Panel"), which contained new recommendations concerning the perspective of economic evaluations, the classification of costs and benefits in a structured table, and the inclusion of related and unrelated healthcare costs in added years of life. ${ }^{22}$ Health technology assessment bodies have also updated their guidance on conducting and appraising economic evaluations. ${ }^{23,24}$

There have also been increasing calls for the use of health economic analysis plans $\mathrm{s}^{25}$ and the use of open source models. ${ }^{26-30}$ The latter may be of particular importance as published economic evaluations are increasingly available in journals with broad data-sharing policies. Increased use of, and guidance for, economic evaluations to support policy decisions in immunisation programmes ${ }^{31,32}$ and global health in lower and middle income countries ${ }^{33}$ have also motivated an update. There has also been an increase in the number of economic evaluations that attempt to capture consequences extending beyond health outcomes, such as equity and distributional effects. ${ }^{34,35}$

Finally, the increased role of stakeholder involvement in health research and health technology assessment, including patients and the public, suggests the need for reporting guidance to recognise a broader audience. ${ }^{36-38}$ All of these developments suggest the scope of guidance for reporting economic evaluations should be expanded and updated.

The objective of this article is to provide a brief overview of the CHEERS 2022 statement, which consists of a 28-item checklist, and an Explanation and Elaboration report with accompanying user tools and guidance. More detailed guidance and illustrative examples on how to use the checklist can be found in the larger Explanation and Elaboration report. ${ }^{39}$

\section{SUMMARY POINTS}

- To ensure health economic evaluations are interpretable and useful for decision making, authors need to provide sufficient detail about the healthcare context and decision under investigation, analytic approach, and findings, and the potential impact on patients, service recipients, and public or application in policy or patient care. 
- This article provides a brief overview of the CHEERS 2022 statement, which provides updated reporting guidance that reflects the need for a broader application to all types of health economic evaluation and health interventions, new methods and developments in the field, as well as the increased role of participation from patients, service recipients, and other key stakeholders.

- The CHEERS 2022 statement consists of a 28-item checklist, and an Explanation and Elaboration report with accompanying user tools and guidance.

- The CHEERS 2022 statement is intended to be used for any form of health economic evaluation and is primarily intended for researchers reporting economic evaluations for peer reviewed journals as well as the peer reviewers and editors assessing them for publication. The statement is not intended as a scoring tool or a tool to assess the appropriateness of methods.

- Budget impact analyses and constrained optimisation studies are beyond the scope of the guidance.

- We anticipate familiarity with reporting requirements will be useful for analysts when planning studies and useful for health technology assessment bodies seeking guidance on reporting, as there is an increasing emphasis on transparency in decision making.

\section{Approach}

The process of revising CHEERS followed that of ISPOR Good Practices Task Force reports ${ }^{40}$ as well as guidance developed by the Enhancing the QUAlity and Transparency Of health Research (EQUATOR) network, ${ }^{41}$ where the CHEERS 2022 update is also registered. An informal review was undertaken of reporting guidelines published since CHEERS, and new items were proposed and consolidated along with the existing CHEERS Checklist. In parallel with this, a task force was convened and a group of patient and public involvement and engagement (PPIE) contributors was formed to review the consolidated checklist and provide suggestions on language and the need for additional items. The draft checklist was finalised by CHEERS Task Force members.

Experts in economic evaluation, as well as those with perspectives in journal editing, decision making, health technology assessment, and commercial life sciences were invited to participate in a modified Delphi Panel ("Delphi") process. Further details on how the Task Force and PPIE members were chosen is available in the Explanation and Elaboration document. ${ }^{39}$ Panellists along with the PPIE contributors were subsequently invited to participate by email and directed to a web based survey. Feedback from each round of the Delphi process was discussed by Task Force members, who ultimately finalised the checklist based on the input provided. A guiding principle for CHEERS is that economic evaluations made available publicly should be understandable, interpretable, and replicable to those who use them.

A completed Guidance for Reporting Involvement of Patients and the Public-Version 2 (GRIPP2) ${ }^{42}$ checklist is in Appendix A. The protocol for the Delphi process, as well as panel composition, size, response rates, and analytic approach can be found in Appendix B.

\section{The CHEERS 2022 statement}

\section{SCOPE}

The CHEERS 2022 statement is intended to be used for any form of health economic evaluation..$^{43}$ This includes analyses that only examine costs and cost offsets (that is, cost analysis) or those that examine both costs and consequences. The latter include analyses that consider health consequences (such as, cost-effectiveness/utility analyses [CEAs/CUAs], cost minimisation, cost-benefit/benefit-cost analyses [CBAs]), and broader measures of benefit and harm to individuals (such as extended CEAs/CBAs), including measures of equity (such as distributional CEAs). While we are aware some studies comparing costs are labelled as CBAs, we recommend the use of this term for studies which include a monetary valuation of health outcomes. Although linked to economic evaluation, budget impact analyses and constrained optimisation studies are beyond the scope of CHEERS guidance, as they require additional reporting that addresses population dynamics and feasibility constraints and are addressed in other guidance reports..$^{44,45}$

The primary audiences for the CHEERS 2022 statement are researchers reporting economic evaluations as well as peer reviewers and editors assessing them for publication. While the statement is not intended to guide the conduct of economic evaluation, familiarity with reporting requirements will be useful for analysts when planning studies. CHEERS may be similarly useful for health technology assessment bodies seeking guidance on reporting, as there is an increasing emphasis on transparency in decision making. ${ }^{46}$ Health technology assessment and the use of economic evaluation is also becoming more commonplace 
globally. ${ }^{3}$ In developing the guidelines, the CHEERS Task Force considered issues that may be specific to regions with developing economies and healthcare systems, including providing examples of these by item in the larger report, ${ }^{39}$ to ensure the reporting guidance will be useful in any social or political context.

CHEERS is relevant for any intervention intended to affect health and should also be widely applicable for both simple and complex interventions, including programmes of care involving researcher-driven or commercialised products (such as drugs, macromolecules, cell, gene, and tissue based therapies, vaccines, and medical devices); public health and social care interventions; processes of care (such as e-health, care coordination, clinical decision rules, clinical pathways, information and communication, medical and allied health services); and re-organisation of care (such as insurance redesign, alternative financing approaches, integrated care, scope of practice change, and workplace interventions).

CHEERS is also applicable to studies based on mathematical modelling or empirical research (such as patient level or cluster level human studies). Although CHEERS can be used for systematic reviews of economic evaluation, its use should be limited to assessing the quality of reporting of a study rather than the quality of its conduct. As there is no validated scoring system for the checklist, using it as a scoring tool could lead to misleading findings and is strongly discouraged.$^{21}$ If used to assess the quality of reporting in a systematic review, a qualitative assessment of completeness of reporting by item is a more appropriate approach. When applying the CHEERS statement, users may need to refer to additional reporting guidance (for example, for randomised controlled trials, patient and public involvement, modelling, health state preference measures), and these are referenced throughout the Explanation and Elaboration report. ${ }^{39}$

\section{How to use CHEERS}

The CHEERS 2022 statement (checklist and Explanation and Elaboration report) replaces the 2013 CHEERS statement, which should no longer be used. The new CHEERS checklist contains 28 items with accompanying descriptions (Table 1). Major changes from CHEERS 2013 are described in Box 1. Checklist items are subdivided into seven main categories: (1) Title; (2) Abstract; (3) Introduction; (4) Methods; (5) Results; (6) Discussion; and (7) Other relevant information. Users of the checklist should first consult the Explanation and Elaboration report ${ }^{39}$ to ensure the appropriate interpretation of each item description.
BOX 1. MAJOR CHANGES IN THE CHEERS 2022 STATEMENT (COMPARED WITH CHEERS 2013)

- Items related to patients or service recipients, the general public, and community or stakeholder involvement and engagement added.

- Language broadened to make CHEERS more widely applicable to cost-benefit/benefit-cost analysis, as well as equity or distributional cost effectiveness.

- Item related to reporting and availability of a health economic analysis plan added.

- Item related to characterising distributional effects added.

- Items distinguishing between model based and study based measures removed.

- Recommendation to report where publicly available models can be found added. Sharing of unlocked models with editors and reviewers encouraged.

Those using the checklist should indicate the section of the manuscript where relevant information can be found. If an item does not apply to a particular economic evaluation (for example, items 11-13 for cost analyses, or items 16 and 22 for non-modelling studies), checklist users are encouraged to report "Not applicable." If information is otherwise not reported, checklist users are encouraged to write "Not reported." Users should avoid the term "Not conducted" as CHEERS is intended to guide and capture reporting.

As before, in developing the CHEERS Statement, the Task Force recognises that the amount of information required for adequate reporting will exceed conventional space limits of most journal reports. Therefore, in making our recommendations, we assume that authors and journals will make necessary information available to readers using online and supplementary appendices or other means.

In addition to the open access Explanation and Elaboration report ${ }^{39}$ we have also made available templates, an interactive form (https://don-husereau.shinyapps.io/CHEERS/), and further educational materials for authors, to facilitate appropriate use of the guidance. We encourage authors to visit the CHEERS ${ }^{47}$ and EQUATOR ${ }^{48}$ websites to locate copies of the checklist, the Explanation and Elaboration report, ${ }^{39}$ links to educational resources, templates, translations, a link to the interactive form and future updates.

\section{Discussion}

We hope this update of the CHEERS statement will be useful to those who need to identify, prepare and interpret reports of health economic evaluations. Despite the promotion and 


\section{TABLE 1 The CHEERS 2022 Checklist}

\begin{tabular}{|c|c|c|c|}
\hline Section/topic & Item No & Guidance for reporting & Reported in section \\
\hline \multicolumn{4}{|l|}{ Title } \\
\hline Title & 1 & $\begin{array}{l}\text { Identify the study as an economic evaluation and specify the } \\
\text { interventions being compared. }\end{array}$ & \\
\hline \multicolumn{4}{|l|}{ Abstract } \\
\hline Abstract & 2 & $\begin{array}{l}\text { Provide a structured summary that highlights context, key } \\
\text { methods, results, and alternative analyses. }\end{array}$ & \\
\hline \multicolumn{4}{|l|}{ Introduction } \\
\hline Background and objectives & 3 & $\begin{array}{l}\text { Give the context for the study, the study question, and its } \\
\text { practical relevance for decision making in policy or practice. }\end{array}$ & \\
\hline \multicolumn{4}{|l|}{ Methods } \\
\hline $\begin{array}{l}\text { Health economic analysis } \\
\text { plan }\end{array}$ & 4 & $\begin{array}{l}\text { Indicate whether a health economic analysis plan was } \\
\text { developed and where available. }\end{array}$ & \\
\hline Study population & 5 & $\begin{array}{l}\text { Describe characteristics of the study population (such as age } \\
\text { range, demographics, socioeconomic, or clinical characteristics). }\end{array}$ & \\
\hline Setting and location & 6 & $\begin{array}{l}\text { Provide relevant contextual information that may influence } \\
\text { findings. }\end{array}$ & \\
\hline Comparators & 7 & $\begin{array}{l}\text { Describe the interventions or strategies being compared and } \\
\text { why chosen. }\end{array}$ & \\
\hline Perspective & 8 & State the perspective(s) adopted by the study and why chosen. & \\
\hline Time horizon & 9 & State the time horizon for the study and why appropriate. & \\
\hline Discount rate & 10 & Report the discount rate(s) and reason chosen. & \\
\hline Selection of outcomes & 11 & $\begin{array}{l}\text { Describe what outcomes were used as the measure(s) of } \\
\text { benefit(s) and harm(s). }\end{array}$ & \\
\hline Measurement of outcomes & 12 & $\begin{array}{l}\text { Describe how outcomes used to capture benefit(s) and harm(s) } \\
\text { were measured. }\end{array}$ & \\
\hline Valuation of outcomes & 13 & $\begin{array}{l}\text { Describe the population and methods used to measure and } \\
\text { value outcomes. }\end{array}$ & \\
\hline $\begin{array}{l}\text { Measurement and valuation } \\
\text { of resources and costs }\end{array}$ & 14 & Describe how costs were valued. & \\
\hline $\begin{array}{l}\text { Currency, price date, and } \\
\text { conversion }\end{array}$ & 15 & $\begin{array}{l}\text { Report the dates of the estimated resource quantities and unit } \\
\text { costs, plus the currency and year of conversion. }\end{array}$ & \\
\hline $\begin{array}{l}\text { Rationale and description of } \\
\text { model }\end{array}$ & 16 & $\begin{array}{l}\text { If modelling is used, describe in detail and why used. Report if } \\
\text { the model is publicly available and where it can be accessed. }\end{array}$ & \\
\hline Analytics and assumptions & 17 & $\begin{array}{l}\text { Describe any methods for analysing or statistically transforming } \\
\text { data, any extrapolation methods, and approaches for validating } \\
\text { any model used. }\end{array}$ & \\
\hline Characterising heterogeneity & 18 & $\begin{array}{l}\text { Describe any methods used for estimating how the results of the } \\
\text { study vary for subgroups. }\end{array}$ & \\
\hline $\begin{array}{l}\text { Characterising distributional } \\
\text { effects }\end{array}$ & 19 & $\begin{array}{l}\text { Describe how impacts are distributed across different } \\
\text { individuals or adjustments made to reflect priority populations. }\end{array}$ & \\
\hline Characterising uncertainty & 20 & $\begin{array}{l}\text { Describe methods to characterise any sources of uncertainty in } \\
\text { the analysis. }\end{array}$ & \\
\hline $\begin{array}{l}\text { Approach to engagement } \\
\text { with patients and others } \\
\text { affected by the study }\end{array}$ & 21 & $\begin{array}{l}\text { Describe any approaches to engage patients or service } \\
\text { recipients, the general public, communities, or stakeholders } \\
\text { (such as clinicians or payers) in the design of the study. }\end{array}$ & \\
\hline
\end{tabular}




\section{TABLE 1 The CHEERS 2022 Checklist (continued)}

\begin{tabular}{|c|c|c|c|}
\hline Section/topic & Item No & Guidance for reporting & Reported in section \\
\hline \multicolumn{4}{|l|}{ Results } \\
\hline Study parameters & 22 & $\begin{array}{l}\text { Report all analytic inputs (such as values, ranges, references) } \\
\text { including uncertainty or distributional assumptions. }\end{array}$ & \\
\hline Summary of main results & 23 & $\begin{array}{l}\text { Report the mean values for the main categories of costs } \\
\text { and outcomes of interest and summarise them in the most } \\
\text { appropriate overall measure. }\end{array}$ & \\
\hline Effect of uncertainty & 24 & $\begin{array}{l}\text { Describe how uncertainty about analytic judgments, inputs, } \\
\text { or projections affect findings. Report the effect of choice of } \\
\text { discount rate and time horizon, if applicable. }\end{array}$ & \\
\hline $\begin{array}{l}\text { Effect of engagement with } \\
\text { patients and others affected } \\
\text { by the study }\end{array}$ & 25 & $\begin{array}{l}\text { Report on any difference patient/service recipient, general } \\
\text { public, community, or stakeholder involvement made to the } \\
\text { approach or findings of the study }\end{array}$ & \\
\hline \multicolumn{4}{|l|}{ Discussion } \\
\hline $\begin{array}{l}\text { Study findings, limitations, } \\
\text { generalisability, and current } \\
\text { knowledge }\end{array}$ & 26 & $\begin{array}{l}\text { Report key findings, limitations, ethical or equity considerations } \\
\text { not captured, and how these could affect patients, policy, or } \\
\text { practice. }\end{array}$ & \\
\hline \multicolumn{4}{|l|}{ Other relevant information } \\
\hline Source of funding & 27 & $\begin{array}{l}\text { Describe how the study was funded and any role of the funder in } \\
\text { the identification, design, conduct, and reporting of the analysis }\end{array}$ & \\
\hline Conflicts of interest & 28 & $\begin{array}{l}\text { Report authors conflicts of interest according to journal } \\
\text { or International Committee of Medical Journal Editors } \\
\text { requirements. }\end{array}$ & \\
\hline
\end{tabular}

increased number of available health economic evaluations, as well as the availability of CHEERS in multiple languages since 2013, there is some indication CHEERS could be more widely and appropriately used. A convenience sample of 50 articles citing CHEERS revealed only $42 \%$ (95\% confidence interval $28 \%$ to $56 \%$ ) made an appropriate use of CHEERS. ${ }^{5}$ This is a similar rate to those observed with other major reporting guidelines (CONSORT, PRISMA, ARRIVE). The same study also found that the inappropriate use of CHEERS has increased from its time of publication.

In creating this update, we also wanted to ensure the broadest possible application of CHEERS. Previous concerns raised about its lack of applicability in cost-benefit analyses (CBAs) were understandable, given original CHEERS guidance leaning strongly towards proving direction for those conducting cost-effectiveness analyses (including cost-utility analyses). This was driven, in part, by the small prevalence and impact of published CBAs at the time of the original CHEERS guidance. However, it is clear that broader characterisations of the benefits of healthcare, in concert with the promotion and publication of other forms of economic evaluation, such as distributional cost-effectiveness analysis, are becoming increasingly important. Health economic evaluation is also finding increasing application across a wider spectrum of health interventions. We hope the revised CHEERS statement addresses these concerns.

We are also aware that the final checklist reflects the perspectives of the Task Force members, PPIE advisors, Delphi Panel members, and peer reviewers involved. While nominal group techniques such as the Delphi approach are intended to minimise the excessive influence of dominant experts in a group, we acknowledge the output of these processes are only as good as the experience and perspectives represented. While a diversity of expertise was sought, it is possible that more could be said for specific applications of CHEERS for interventions that have impacts beyond health (for example, educational, environmental, social care). We would encourage those who see opportunities to expand CHEERS 2022 items, or to create additional reporting guidance that provides clarification in specific areas, to work with members of the CHEERS Task Force to develop CHEERS extensions in these areas.

The updated guidance also anticipates future developments in the conduct and reporting of published health economic evaluations. These include the use of health economic analysis plans, model sharing, and the increasing involvement of stakeholders in health research, including engagement with communities, patients, and the public. 
While some on the Delphi Panel suggested that these developments did not warrant their own reporting items, the Task Force ultimately felt addressing these developments through the creation of separate items could foster awareness of their use and development.

As there is an increasing need for clarity of information to support healthcare decision making and attention to healthcare expenditure, we anticipate the role of published health economic evaluation to become more important. While we hope the CHEERS 2022 statement and accompanying resources will ultimately improve the quality of reporting (and decision making), the impact of the original CHEERS statement on reporting quality is still uncertain. A formal evaluation study is ongoing, and results will be available in 2022.49 In the meantime, we have focused our attention on strategies to increase the appropriate use of CHEERS, including creating a wider range of tools and resources for editors and authors, seeking endorsement across a larger group of journals, and increasing outreach efforts.

We also recognise that researchers may wish to translate CHEERS 2022 into other languages. In these cases, we would encourage appropriate methods ${ }^{41,50}$ and collaboration with Task Force members to ensure consistency with CHEERS. We encourage authors, peer reviewers, and editors to regularly consult the CHEERS 2022 webpage and to provide feedback on how it can be improved.

\section{Conclusion}

This summary article presents the new CHEERS 2022 28-item checklist, and recommendations for each item. The CHEERS 2022 statement is primarily intended for researchers reporting economic evaluations for peerreviewed journals as well as the peer reviewers and editors assessing them for publication. However, we anticipate familiarity with reporting requirements will be useful for analysts when planning studies. It may also be useful for health technology assessment bodies seeking guidance on reporting, as there is an increasing emphasis on transparency in decision-making.

\section{WE THANK THE FOLLOWING WHO PARTICIPATED IN THE STUDY}

The Patient and Public Involvement and Engagement (PPIE) Advisory Group: Ivett Jakab, Emma Kinloch, Eric Low, Jean Mossman, Declan Noone, Phil Posner, and Jo Watson.

The Editors Advisory Group: Wendy Babidge, Lyn Beamesderfer, Dior Beerens, Chris Carswell, Tillie Cryer, Ana Donnelly, Manuel Espinoza, Dan Greenberg, Wolfgang Greiner, Laura Happe, Mickaël Hiligsmann, Christine Laine, Lin Lee, Ken Lee, Elizabeth Loder, Natalie Pafitis, Julia Robinson Kenneth Stein, Eva Szunyogova, Wim Weber, Timothy Wrightson, and Brian Zikmund-Fisher.

Participants in the Delphi Panel exercise: Marie-Claude Aubin, Marc Berger, John Campbell, Doug Coyle, Matthew Dyer Richard Edlin, Rita Faria, Veronica Gallegos, Alastair Gray, Scott Grosse, Jason Guertin, Dyfrig Hughes, Florencia Hutter, Denny John, Hanin Farhana Kamaruzaman, David Kim, Murray Krahn, Dan Moldaver, $\mathrm{Ku}$ Abd Rahim Ku Nurhasni, Daniela Vianna Pachito, Michael Paulden, Clinton Pecenka, Andrés Pichon-Riviere, John Powell, Lisa Prosser, Dean Regier, Anna Ringborg, Rossana Rivas, Chris Sampson, Marisa Santos, Paul Scuffham, Mark Sculpher, Katia Senna, Eldon Spackman, Lotte Steuten, David Tamblyn, Kilgore Trout, Dick Willke, and Torbjorn Wisloff.

Additional ISPOR reviewers who commented on our drafts: Tadesse Abegaz, Alex Kostyuk, Kelly Lenahan, Nan Luo, Joshua Soboil, Richard White, and members of the PPIE.

Thanks to David Moher for initial advice on approach, and a very special final thanks to Elizabeth Molsen.
Contributors: DH is Task Force co-chair and the submitting and corresponding author; MD is a Task Force co-chair. All other authors (FA, EBG, AHB, CC, LC, NC DG, EL, JM, CDM, SP, RFP, and SS- listed in alphabetical order by surname) and the $\mathrm{co}^{-}$ chairs conceived this paper and designed the Delphi survey conducted to inform the guideline content. DH conducted a literature review, administered the Delphi survey and analysed the data for both. DH and MD prepared materials for each meeting and led the drafting and editing of the article. DH, MD, FA, AHB, EBG, CC, LC, NC, DG, EL, JM, CDM, SP, RFP, and SS drafted particular sections of the article. MD and SS led the PPIE advisory group. DH and CC led the Editors Advisory Group. All authors were involved in revising the article critically for important intellectual content. All authors approved the final version of the article. DH is the guarantor of this work. The corresponding author attests that all listed authors meet authorship criteria and that no others meeting the criteria have been omitted.

David Moher served as scientific advisor and reviewed the initial proposal as well as attended initial meetings; all members of the PPIE (Ivett Jakab, Emma Kinloch, Eric Low, Jean Mossman, Declan Noone, Phil Posner, and Jo Watson) critically reviewed the initial checklist and suggested and provided review and advice on subsequent drafts of the checklist and Explanation and Elaboration report. Members of the PPIE were invited to participate in the Delphi Panel exercise. All members of the PPIE, and Delphi Panel were invited to review drafts of the checklist and accompanying report.

\section{FUNDING}

Funding to support ongoing meetings was provided by ISPOR - The Professional Society for Health Economics and Outcomes Research. The funders had no role in considering the study design or in the collection, analysis, interpretation of data, or writing of the report. Funding for DH and the Delphi Panel exercise was provided by 9363980 Canada Inc. SS is part funded by the NIHR Applied Research Collaboration (ARC) West Midlands, the NIHR Health Protection Research Unit (HPRU) Gastrointestinal Infections, and the NIHR HPRU Genomics and Enabling data. 


\section{COMPETING INTERESTS}

All authors have completed the ICMJE uniform disclosure form and declare no competing interests.

Provenance and peer review: Not commissioned; externally peer reviewed.

\section{WEB EXTRA \\ MATERIAL SUPPLIED BY THE AUTHOR}

Appendix A: A completed Guidance for Reporting Involvement of Patients and the Public-Version 2 (GRIPP2) checklist

Appendix B: Protocol for the Delphi process

\section{PUBLICATION STATEMENT}

This article is a joint publication by Applied Health Economics and Health Policy, BJOG, BMC Health Services Research, BMC Medicine, BMC Public Health, BMJ, Clinical Therapeutics, Health Policy Open, International Journal of Technology Assessment in Health Care, Journal of Managed Care $\&$ Specialty Pharmacy, Journal of Medical Economics, MDM Policy \& Practice, Pharmacoeconomics, The European Journal of Health Economics, Value in Health, and Value in Health Regional (en español). Each publisher holds its own copyright or has licensed the content for use, with the authors retaining copyright. The BMJ managed the peer review process for this article on behalf of all journals.

C2022 the Author(s) This article is a joint publication by Applied Health Economics and Health Policy, BJOG, BMC Health Services Research, BMC Medicine, BMC Public Health, BMJ, Clinical Therapeutics, Health Policy Open, International Journal of Technology Assessment in Health Care, Journal of Managed Care \& Specialty Pharmacy, Journal of Medical Economics, MDM Policy \& Practice, Pharmacoeconomics, The European Journal of Health Economics, Value in Health, and Value in Health Regional (en español). Each publisher holds its own copyright or has licensed the content for use, with the authors retaining copyright. The BMJ managed the peer review process for this article on behalf of all journals. This article is published under the Creative Commons CC-BY license.

\section{REFERENCES}

1. Pitt C, Goodman C, Hanson K.

Economic evaluation in global perspective: a bibliometric analysis of the recent literature. Health Econ. 2016;25(Suppl 1): 9-28. doi:10.1002/hec.3305

2. Neumann PJ, Thorat T, Shi J, Saret CJ, Cohen JT. The changing face of the costutility literature, 1990-2012. Value Health. 2015;18:271-7. doi:10.1016/j.jval.2014.12.002

3. Panzer AD, Emerson JG, D'Cruz B, et al. Growth and capacity for costeffectiveness analysis in Africa. Health Econ. 2020;29:945-54. doi:10.1002/hec.4029

4. Husereau D, Drummond M, Petrou S, et al; ISPOR Health Economic Evaluation Publication Guidelines-CHEERS Good Reporting Practices Task Force. Consolidated Health Economic Evaluation Reporting Standards (CHEERS)-explanation and elaboration: a report of the ISPOR Health Economic Evaluation Publication Guidelines Good Reporting Practices Task Force. Value Health. 2013;16:231-50. doi:10.1016/j. jval.2013.02.002

5. Caulley L, Catalá-López F, Whelan J, et al. Reporting guidelines of health research studies are frequently used inappropriately. J Clin Epidemiol. 2020;122:87-94. doi:10.1016/j.jclinepi.2020.03.006

6. Emerson J, Panzer A, Cohen JT, et al. Adherence to the iDSI reference case among published cost-per-DALY averted studies. PLoS One. 2019;14:e205633. doi:10.1371/journal.pone.0205633

7. Task Force on Principles for Economic Analysis of Health Care Technology. Economic analysis of health care technology. A report on principles. Ann Intern Med. 1995;123:61-70. doi:10.7326/0003-4819-1231-199507010-00011

8. Gold MR. Cost-effectiveness in health and medicine. Oxford University Press, 1996.

9. Drummond MF, Jefferson TO; The BMJ Economic Evaluation Working Party. Guidelines for authors and peer reviewers of economic submissions to the BMJ. BMJ. 1996;313:275-83. doi:10.1136/ bmj. 313.7052 .275
10. Siegel JE, Weinstein MC, Russell LB, Gold MR; Panel on Cost-Effectiveness in Health and Medicine. Recommendations for reporting cost-effectiveness analyses. JAMA. 1996;276:1339-41. doi:10.1001/ jama.1996.03540160061034

11. Nuijten MJ, Pronk MH, Brorens MJA, et al. Reporting format for economic evaluation. Part II: Focus on modelling studies. Pharmacoeconomics. 1998;14: 259-68. doi:10.2165/00019053-199814030$\underline{00003}$

12. Vintzileos AM, Beazoglou T. Design, execution, interpretation, and reporting of economic evaluation studies in obstetrics. Am J Obstet Gynecol. 2004;191:1070-6. doi:10.1016/j.ajog.2004.05.021

13. Drummond M, Manca A, Sculpher M. Increasing the generalizability of economic evaluations: recommendations for the design, analysis, and reporting of studies. Int J Technol Assess Health Care. 2005;21:165-71. doi:10.1017/ $\underline{\mathrm{S} 0266462305050221}$

14. Ramsey SD, Willke RJ, Glick H, et al. Cost-effectiveness analysis alongside clinical trials II-An ISPOR Good Research Practices Task Force report. Value Health. 2015;18:161-72. doi:10.1016/j.jval.2015.02.001

15. Goetghebeur MM, Wagner M, Khoury H, Levitt RJ, Erickson LJ, Rindress D. Evidence and Value: Impact on DEcisionMaking-the EVIDEM framework and potential applications. BMC Health Serv Res. 2008;8:270. doi:10.1186/1472-6963-8-270

16. Davis JC, Robertson MC, Comans T, Scuffham PA. Guidelines for conducting and reporting economic evaluation of fall prevention strategies. Osteoporos Int. 2011;22:2449-59. doi:10.1007/ s00198-010-1482-0

17. Petrou S, Gray A. Economic evaluation alongside randomised controlled trials: design, conduct, analysis, and reporting. BMJ. 2011;342:d1548. doi:10.1136/bmj.d1548

18. Petrou S, Gray A. Economic evaluation using decision analytical modelling: design, conduct, analysis, and reporting. BMJ. 2011;342:d1766. doi:10.1136/bmj.d1766 
19. Sanghera S, Frew E, Roberts T. Adapting the CHEERS Statement for reporting cost-benefit analysis. Pharmacoeconomics. 2015;33:533-4. doi:10.1007/s40273-015-0265-z

20. Walker DG, Wilson RF, Sharma R, et al. Best practices for conducting economic evaluations in health care: a systematic review of quality assessment tools. Agency for Healthcare Research and Quality, 2012. https://www.ncbi.nlm.nih. gov/books/NBK114545

21. Jüni P, Witschi A, Bloch R, Egger M. The hazards of scoring the quality of clinical trials for meta-analysis. JAMA. 1999;282:1054-60. doi:10.1001/ jama.282.11.1054

22. Sanders GD, Neumann PJ, Basu A, et al. Recommendations for conduct, methodological practices, and reporting of cost-effectiveness analyses: second panel on cost-effectiveness in health and medicine. JAMA. 2016;316:1093-103. doi:10.1001/jama.2016.12195

23. CADTH.ca. Guidelines for the economic evaluation of health technologies: Canada. 2015. https:// www.cadth.ca/about-cadth/howwe-do-it/methods-and-guidelines/ guidelines-for-the-economic-evaluationof-health-technologies-canada

24. EUnetHTA European Network for Health Technology Assessment. Practical considerations when critically assessing economic evaluations. Guidance document. 2021. https://eunethta. eu/wp-content/uploads/2020/03/ EUnetHTA-JA3WP6B2-5-GuidanceCritical-Assessment-EE_v1-0.pdf

25. Thorn J, Ridyard C, Hughes D, et al. Health economics analysis plans: Where are we now? Value Health. 2016;19:A397. doi:10.1016/j.jval.2016.09.291

26. Dunlop WCN, Mason N, Kenworthy J, Akehurst RL. Benefits, challenges and potential strategies of open source health economic models. Pharmacoeconomics. 2017;35:125-8. doi:10.1007/s40273-016$\underline{0479-8}$
27. Jansen JP, Incerti D, Linthicum MT. Developing open-source models for the US health system: practical experiences and challenges to date with the opensource value project. Pharmacoeconomics. 2019;37:1313-20. doi:10.1007/s40273-019$\underline{00827-z}$

28. Smith R, Schneider P. Making health economic models Shiny: A tutorial. Wellcome Open Res 2020;5:69. doi:10.12688/wellcomeopenres.15807.2

29. ISPOR. Open source models. https://www.ispor.org/member-groups/ special-interest-groups/open-sourcemodels

30. Cohen JT, Neumann PJ, Wong JB. A call for open-source cost-effectiveness analysis. Ann Intern Med. 2017;167:432-3. doi:10.7326/M17-1153

31. WHO. WHO guide for standardization of economic evaluations of immunization programmes. https://www.who.int/ publications/i/item/WHO-IVB-19.10

32. Mauskopf J, Standaert B, Connolly MP, et al. Economic analysis of vaccination programs: An ISPOR Good Practices for Outcomes Research Task Force Report. Value Health. 2018;21:1133-49. doi:10.1016/j. jval.2018.08.005

33. Wilkinson T, Sculpher MJ, Claxton K, et al. The International Decision Support Initiative reference case for economic evaluation: an aid to thought. Value Health. 2016;19:921-8. doi:10.1016/j. jval.2016.04.015

34. Cookson R, Drummond M, Weatherly H. Explicit incorporation of equity considerations into economic evaluation of public health interventions. Health Econ Policy Law. 2009;4:231-45. doi:10.1017/ $\underline{\mathrm{S} 1744133109004903}$

35. Cookson R, Griffin S, Norheim OF, Culyer AJ, Chalkidou K. Distributional cost-effectiveness analysis comes of age. Value Health. 2021;24:118-20. doi:10.1016/j. jval.2020.10.001

36. Lorgelly PK. Patient and public involvement in health economics and outcomes research. Patient. 2021;14:379-80. doi:10.1007/s40271-021-00505-3
37. Ryan M, Moran PS, Harrington P, et al. Contribution of stakeholder engagement to the impact of a health technology assessment: an Irish case study. Int J Technol Assess Health Care. 2017;33:424-9. doi:10.1017/S026646231700085X

38. Hawton A, Boddy K, Kandiyali R, Tatnell L, Gibson A, Goodwin E. Involving patients in health economics research: "The PACTS Principles". Patient. 2021:14:429-34. doi:10.1007/ s40271-020-00461-4

39. Husereau D, Drummond M, Augustovski F, et al. Consolidated Health Economic Evaluation Reporting Standards 2022 (CHEERS 2022) Explanation and Elaboration: A report of the ISPOR CHEERS II Good Practices Task Force. Value Health. 2022; doi:10.1016/j. jval.2021.10.008

40. Malone DC, Ramsey SD, Patrick DL, et al. Criteria and Process for Initiating and Developing an ISPOR Good Practices Task Force Report. Value Health. 2020;23: 409-15. doi:10.1016/j.jval.2020.03.001

41. Moher D, Schulz KF, Simera I, Altman DG. Guidance for developers of health research reporting guidelines. PLoS Med. 2010;7:e1000217. doi:10.1371/journal. pmed.1000217

42. Staniszewska S, Brett J, Simera I, et al. GRIPP2 reporting checklists: tools to improve reporting of patient and public involvement in research. BMJ. 2017;358:j3453. doi:10.1136/bmj.j3453

43. Drummond M. Methods for the economic evaluation of health care programmes. 4th ed. Oxford University Press, 2015.

44. Sullivan SD, Mauskopf JA, Augustovski F, et al. Budget impact analysis-principles of good practice: report of the ISPOR 2012 Budget Impact Analysis Good Practice II Task Force. Value Health. 2014;17:5-14. doi:10.1016/j.jval.2013.08.2291

45. Crown W, Buyukkaramikli N, Thokala P, et al. Constrained optimization methods in health services research-an introduction: Report 1 of the ISPOR Optimization Methods Emerging Good Practices Task Force. Value Health. 2017;20:310-9. doi:10.1016/j.jval.2017.01.013 
46. Bond K, Stiffell R, Ollendorf DA. Principles for deliberative processes in health technology assessment. Int $\mathrm{J}$ Technol Assess Health Care. 2020;1-8. doi:10.1017/S0266462320000550

47. ISPOR. Consolidated Health Economic Evaluation Reporting Standards (CHEERS). https://www.ispor.org/CHEERS
48. Altman DG, Simera I. A history of the evolution of guidelines for reporting medical research: the long road to the EQUATOR Network. J R Soc Med. 2016;109:67-77. doi:10.1177/01410768 15625599

49. Catalá-López F, Caulley L, Ridao M, et al. Reproducible research practices, openness and transparency in health economic evaluations: study protocol for a cross-sectional comparative analysis. BMJ Open. 2020;10:e034463. doi:10.1136/ bmjopen-2019-034463
50. Sperber AD. Translation and validation of study instruments for crosscultural research. Gastroenterology. 2004;126(Suppl 1):S124-8. doi:10.1053/j. gastro.2003.10.016 